\title{
Selective incorporation of iododeoxyuridine into DNA of hepatic metastases versus normal human liver
}

\begin{abstract}
Fourteen patients received 5-iodo- $2^{1}$-deoxyuridine (IdUrd) before surgery for placement of a hepatic arterial catheter. Biopsy specimens were obtained at the time of surgery and incorporation of IdUrd into deoxyribonucleic acid (DNA) in tumor and normal hepatic tissue was measured by HPLC and used as an index of drug selectivity. Over a 3-day intravenous infusion of IdUrd at $1000 \mathrm{mg} / \mathrm{m}^{2} /$ day, substitution for thymidine in tumor DNA averaged 3.1\%. Normal hepatic DNA contained $<1 \%$ substitution by IdUrd. Arterial delivery of IdUrd increased levels in DNA, whereas modulation with fluorodeoxyuridine produced mixed results. In six patients, flow cytometric analysis showed that the tumor contained a median of $32 \%$ of tumor cells that had incorporated IdUrd in 3 days, corresponding to a potential doubling time of only 10 days. Thymidylate synthetase activity in tumors was 20 -fold greater than in normal liver tissue, whereas thymidine kinase activity was twofold greater in tumors. These pharmacologic studies encourage further clinical trials of IdUrd as a cytotoxic agent or radiosensitizer. (Clin PHARMACOL THer 1988;44:369-75.)

\section{Paul A. J. Speth, MD,* Timothy J. Kinsella, MD,** Alfred E. Chang, MD,*** Raymond W. Klecker, Jr., BS, Karl Belanger, MD,,$^{* * *}$ and Jerry M. Collins, PhD Bethesda, $M d$.}

Selectivity is the cornerstone of successful cytotoxic therapy of cancer. A major drawback to clinically evaluating the selective impact of various therapeutic maneuvers is an inability to directly examine the target tissue, namely, the tumor. Most tumors are inaccessible to sampling, except through a major surgical intervention. Some tumors can be reached by needle biopsy, but the amount of tissue obtained is small and may not represent the majority of the tumor.

From the Clinical Pharmacology, Radiation Oncology, and Surgery Branches, National Cancer Institute

Received for publication Jan. 20, 1988; accepted April 18, 1988.

Reprint requests: Jerry M. Collins, PhD, Food and Drug Administration, HFD-401/Parklawn, Rockville, MD 20857.

*Supported by grants from the Niels Stensen Foundation, the NCI-EORTC exchange program, and the Netherlands Cancer Foundation, KWF. Present address: St. Radboud University Hospital, Department of Medical Oncology, Nijmegen, The Netherlands.

**Present address: Department of Human Oncology, University of Wisconsin, Madison, WI 53792.

***Present address: Department of Surgery, University of Michigan Medical Center, Ann Arbor, MI 48109.

****Present address: Institut du Cancer de Montreal, Canada.
Because it is ethically difficult to justify performing surgical procedures primarily for purposes of research, an alternative approach is to structure research around surgical interventions that are already planned and justified for other purposes. Biopsy samples obtained at the time of scheduled surgery can be used for research purposes. These examinations can be made much more enlightening if the patient has received some type of antitumor treatment before surgery. A clear demonstration of the safety of any presurgical treatment is required, especially in light of any interference with the scheduled surgery, coagulation, or the wound healing process.

We have undertaken a clinical evaluation of the use of intrahepatic arterial infusion of 5-iodo-2'deoxyuridine (IdUrd) in patients with hepatic metastases from colorectal carcinoma. ${ }^{1}$ All patients required laparotomy for placement of a semipermanent catheter in the hepatic artery. This surgical requirement provided a unique opportunity to obtain biopsy specimens of the target tumor and surrounding normal tissue. To maximize the information obtained from these specimens, 
all patients received a 3-day infusion of IdUrd before surgery. The effect of various maneuvers that might enhance selectivity (changes in dose rate, route of delivery, biochemical modulation) could be readily examined with this model system.

IdUrd is a competitive analog of thymidine (dThd). Its cytotoxic activity and radiosensitizing properties have been demonstrated both in vitro ${ }^{2.3}$ and in vivo. ${ }^{4.6}$ IdUrd was chosen for our study because this drug has never been adequately evaluated in clinical trials and because its high total body clearance ${ }^{\gamma}$ was a favorable property for intraarterial use.$^{8}$ Its mechanism of action is thought to be related to incorporation into deoxyribonucleic acid (DNA), which is readily measurable in tissue samples. ${ }^{9-11}$ Hepatic metastases were considered to be an ideal setting, because a dThd analog could maximally exploit differences between dividing tumor cells and nondividing liver cells.

In this study, incorporation of IdUrd into the DNA of normal hepatic tissue and tumor tissue was used as an index of drug selectivity. DNA levels were determined by enzymatic degradation and HPLC measurement of nucleosides. The fraction of tumor cells that divided during the 3-day infusion was determined by flow cytometric analysis. A comparative pharmacokinetic study of intravenous vs. intraarterial delivery of IdUrd is presented, as well as the impact of 5-fluoro2 '-deoxyuridine (FdUrd) on IdUrd incorporation into DNA. Furthermore, we estimated the hepatic extraction for IdUrd and measured the patterns of two key enzymes (thymidylate synthetase and thymidine kinase) in normal and tumor tissue.

\section{MATERIAL AND METHODS}

Clinical. Patients with histologically confirmed, unresectable tumors located in the liver (metastases from primary colorectal carcinoma) were eligible for study. All patients gave informed consent to participate and the study was approved by the Institutional Clinical Research Committee.

IdUrd (NSC 39661) for infusion was supplied by the National Cancer Institute. FdUrd was obtained from commercial suppliers. When coadministered, the two drugs were mixed together and infused simultaneously. Patients were admitted before surgery and an IMED Corp. infusion pump (San Diego, Calif.) was used to deliver a 3-day continuous infusion of IdUrd or FdUrd plus IdUrd. The drug solution was infused through either a peripheral vein or a flexible silicone rubber catheter that had been originally placed into the hepatic artery for purposes of percutaneous diagnostic angiography.
The infusion rates (in milligrams per square meter per day) for IdUrd or IdUrd plus FdUrd were approximately the maximally tolerated values for a 14-day infusion period, based on our experience. " Because the infusion period for this study was limited to 3 days, it was expected that there would be no toxicity produced at these dosages.

At the time of laparotomy for placement of the semipermanent catheter in the hepatic artery, biopsy specimens of tumor and normal tissue were taken for pharmacologic studies. Two weeks after surgery, patients began the intraarterial therapeutic portion of the study. The clinical results (toxicity and response) of the treatment portion of this study will be reported separately. ${ }^{1}$

Enzyme studies. Protein concentrations of the enzyme extract were determined by the method of Bradford. ${ }^{12}$ The Biorad assay kit (Richmond, Calif.) was used with bovine serum albumin standards.

The thymidylate synthetase (TS; EC 2.1.1.45) activity was determined by the tritium-release method of Armstrong and Diasio. ${ }^{13}$ After addition of methylene tetrahydrofolate, the reaction was initiated with $\left[5-{ }^{3} \mathrm{H}\right]-$ deoxyuridine monophosphate $(2 \mathrm{Ci} / \mathrm{mmol}$; Moravek Biochemicals, Brea, Calif.) at a final concentration of $20 \mu \mathrm{mol} / \mathrm{L}$. The mixture was incubated at $37^{\circ} \mathrm{C}$ for 40,80 , and 120 minutes. An aliquot of each sample was mixed with charcoal (Norit-A; Baker, Phillipsburg, N.J.), dextran, and bovine serum albumin and centrifuged for 5 minutes (Eppendorf centrifuge model 5414; Brinkman Instruments Inc., Westbury, N.Y.). The supernatant was transferred to a second tube, again mixed with the charcoal solution, and centrifuged for another 5 minutes. The supernatant was transferred to a vial, scintillation fluid was added, and the sample was counted (model 2000CA liquid scintillation analyzer; Packard Instruments Company, Sterling, Va.).

The thymidine kinase (TK; EC 2.7.1.21) activity was determined according to Taylor et al. ${ }^{14}$ The supernatant from the homogenate was further diluted $1: 5$, because excess enzyme appeared to be inhibitory. ${ }^{15}$ After addition of adenosine triphosphate and $\mathrm{MgCl}_{2}$, the reaction was initiated with [methyl- $\left.{ }^{3} \mathrm{H}\right]-\mathrm{dThd}(1 \mathrm{Ci} / \mathrm{mmol}$; Moravek Biochemicals) at a final concentration of 50 $\mu \mathrm{mol} / \mathrm{L}$. After 10, 20, and 30 minutes of incubation at $37^{\circ} \mathrm{C}, 50 \mu \mathrm{l}$ was spotted onto ion exchange paper (2.3 cm DE81 disk; Whatman, Maidstone, U.K.). The disks were washed three times in ammonium formate, transferred to $95 \%$ ethanol, and dried on a hot plate. The disks were placed in vials and soaked in $1.5 \mathrm{~N}$ $\mathrm{NaCl} / 0.5 \mathrm{~N} \mathrm{HCl}$ before liquid scintillation counting.

Laboratory studies. Two blood samples were drawn 
during the presurgical infusion and two were drawn during subsequent treatment cycles. Blood was collected in Vacutainer tubes (Becton Dickinson, Rutherford, N.J.) and immediately placed on ice. After centrifugation, plasma was collected and stored at $-20^{\circ} \mathrm{C}$ until analysis by previously reported HPLC methods. ${ }^{7}$

Biopsies obtained at the time of placement of the semipermanent intraarterial catheter were immediately placed on ice. Portions were used for routine pathologic examination and flow cytometric analysis. A tissue homogenate for DNA incorporation and enzyme studies was prepared on ice by diluting the remaining minced tissue with four volumes of ice-cold homogenization buffer (Tris- $\mathrm{HCl}, 200 \mathrm{mmol} / \mathrm{L}, \mathrm{pH} \mathrm{7.4}$; 2-mercaptoethanol, $200 \mathrm{mmol} / \mathrm{L} ; \mathrm{NaF}, 100 \mathrm{mmol} / \mathrm{L}$; and cytidylate, $15 \mathrm{mmol} / \mathrm{L}$ ). The tissue was homogenized mechanically and sonicated with five 10 -second bursts at $50 \mathrm{~W}$ (Model W-225; Ultrasonics, Inc., Farmingdale, N.Y.). One hundred microliters of homogenate was digested for determination of IdUrd incorporation into DNA..$^{9-11}$ Nucleic acids in the tissue homogenate were precipitated by trichloroacetic acid. After hydrolysis of ribonucleic acid (RNA) with sodium hydroxide, the acid-soluble ribonucleotides were discarded. DNA was enzymatically digested to the nucleoside level. Aliquots of the digest were analyzed by HPLC. The nucleosides were detected simultaneously at $254 \mathrm{~nm}$ and at $300 \mathrm{~nm}$. After a 30-minute spin $(25000 \times \mathrm{g}$, Sorvall RC5; Dupont Instruments, Wilmington, Del.) of the remaining homogenate, the supernatant was used for measurement of protein content and enzymatic activity. The pellet could be used for a duplicate determination of IdUrd incorporation into DNA.

Flow cytometry. A single-cell suspension was prepared by mincing tissue through an $88 \mu \mathrm{m}$ gauze and washing with phosphate-buffered saline solution. The pellet was resuspended in the buffer and three parts of $95 \%$ ethanol was added. This suspension was stored at $-20^{\circ} \mathrm{C}$ until analysis, usually within 1 week. At the time of analysis, the suspension was centrifuged and the pellet was resuspended in $2 \mathrm{ml}$ phosphate-buffered saline solution to which $2 \mathrm{ml} 4 \mathrm{~N} \mathrm{HCl}$ was added. After 30 minutes at room temperature, the cells were washed with sodium borate $(0.1 \mathrm{~mol} / \mathrm{L}, \mathrm{pH} 8.5)$. One million cells were resuspended in $50 \mu$ phosphate-buffered saline solution containing $0.5 \%$ Tween 20 (Sigma Chemical, St. Louis, Mo.) to which $20 \mu \mathrm{l}$ of monoclonal antibody solution was added (Anti-BrdU, fluorescein conjugate; Becton Dickinson Immunocytometry Systems, Mountain View, Calif.). After 30 minutes at
Table I. Comparison of intravenous vs. intraarterial delivery of a 3-day infusion of $1000 \mathrm{mg} \mathrm{IdUrd} / \mathrm{m}^{2} /$ day given before biopsy as determined by HPLC

\begin{tabular}{ccccc}
\hline & & \multicolumn{3}{c}{ IdUrd level in DNA } \\
\cline { 3 - 5 } Patient & Route & $\begin{array}{c}\text { Normal } \\
\text { liver }\end{array}$ & $\begin{array}{l}\text { Right } \\
\text { tumor }\end{array}$ & $\begin{array}{c}\text { Left } \\
\text { tumor }\end{array}$ \\
\hline A & iv & $*$ & $4.5 \%$ & $2.5 \%$ \\
B & iv & $0.6 \%$ & $4.1 \%$ & $4.2 \%$ \\
C & iv & $0.8 \%$ & $3.0 \%$ & $2.9 \%$ \\
D & iv & $0.4 \%$ & $2.1 \%$ & $1.7 \%$ \\
E & iv & $0.3 \%$ & $3.1 \%$ & $2.6 \%$ \\
F & ia & $2.4 \%$ & $3.8 \%$ & $5.7 \%$ \\
G & ia & $0.8 \%$ & $5.9 \%$ & $*$ \\
H $\dagger$ & ia & $1.0 \%$ & $10.5 \%$ & $1.6 \%$ \\
\hline
\end{tabular}

iv, intravenous; ia, intraarterial.

* No sample obtained.

$\doteqdot$ Perfused right lobe only.

room temperature, the suspension was washed in phosphate-buffered saline solution/Tween 20 and resuspended in $100 \mu \mathrm{l}$ propidium iodide $(5 \mu \mathrm{g} / \mathrm{ml}$ in phosphate-buffered saline solution; Sigma).

Four-parameter flow cytometric analysis was performed on a FACS 440 flow cytometer (Becton Dickinson Immunocytometry Systems) equipped with a $5 \mathrm{~W}$ argon laser (Model 164; Spectraphysics, Piscataway, N.J.) operating at $488 \mathrm{~nm}$ and using $200 \mathrm{~mW}$. Green fluorescence from the fluorescein isothiocyanate antibody-labeled cells was collected through a DF535/15 bandpass filter (Omega Optical, Brattleboro, $\mathrm{Vt}$.) and recorded as a measure of the amount of incorporation of IdUrd. Red fluorescence (DNA content) as well as forward and perpendicular light scatter was also recorded. In each sample, 20,000 cells were counted and histograms of the distribution of IdUrd in each cell were obtained. The mean values were expressed in arbitrary fluorescence units per cell (FU/cell).

\section{RESULTS}

Fourteen patients entered this study; 12 were male and 2 were female. Median age was 58 years (range 44 to 68 years). Performance status was $70 \%$ to $100 \%$ (Karnofsky). There was no toxicity observed subsequent to any infusion in this study.

For five patients who received a 3-day infusion of intravenous IdUrd $\left(1000 \mathrm{mg} / \mathrm{m}^{2} /\right.$ day $)$ before surgery, the incorporation of IdUrd into tumor DNA averaged $3.1 \%$, with a range from $1.7 \%$ to $4.5 \%$ (Table I, patients A to E). In these patients, bilobar hepatic metastases were present and tumor biopsy specimens from both 
Table II. Effect of dose rate and coadministration of FdUrd on replacement by IdUrd of dThd in DNA with 3-day continuous intravenous infusions

\begin{tabular}{cccccc}
\hline & & & \multicolumn{2}{c}{ IdUrd level in DNA } \\
\cline { 4 - 6 } Patient & $\begin{array}{c}\text { Dose FdUrd } \\
\left(\mathrm{mg} / \mathrm{m}^{2} / \text { day }\right)\end{array}$ & $\begin{array}{c}\text { Dose IdUrd } \\
\left(\mathrm{mg} / \mathrm{m}^{2} / \text { day }\right)\end{array}$ & $\begin{array}{c}\text { Normal } \\
\text { liver }\end{array}$ & $\begin{array}{c}\text { Right } \\
\text { tumor }\end{array}$ & $\begin{array}{c}\text { Left } \\
\text { tumor }\end{array}$ \\
\hline Mean $\pm \mathrm{SD}^{*}$ & 0 & 1000 & $0.5 \pm 0.1 \%$ & $3.1 \% \pm 0.3 \%$ \\
$\mathrm{I}$ & 0 & 400 & $0.3 \%$ & $1.3 \%$ & $1.5 \%$ \\
$\mathrm{~J}$ & 2.4 & 450 & $5.6 \%$ & $4.5 \%$ & $\dagger$ \\
$\mathrm{K}$ & 2.4 & 450 & $0.5 \%$ & $5.2 \%$ & $\dagger$ \\
$\mathrm{L}$ & 2.4 & 450 & $0.4 \%$ & $0.8 \%$ & $\dagger$ \\
$\mathrm{N}$ & 2.4 & 450 & $<0.2 \%$ & $1.4 \%$ & $\dagger$ \\
$\mathrm{P}$ & 2.4 & 450 & $<0.2 \%$ & $1.3 \%$ & $\dagger$ \\
\hline
\end{tabular}

* Mean values for the five patients listed in Table 1 (biopsies of 10 tumors and 4 normal livers).

†No sample obtained.

the left and right lobes were obtained. In contrast, samples of normal liver from these patients had $<1 \%$ replacement of dThd in DNA.

When the same dose of IdUrd $\left(1000 \mathrm{mg} / \mathrm{m}^{2} /\right.$ day for 3 days) was delivered via a percutaneous catheter placed in the common hepatic artery (Table I, patients $F$ and $G$ ), incorporation of IdUrd into tumor DNA was up to twofold greater than for the intravenous route. In patient $\mathrm{H}$, the infusion catheter was selectively placed in the right branch of the hepatic artery and tumor DNA levels in the right lobe were $10.5 \%$, whereas tumor DNA levels in the left lobe were only $1.6 \%$ (Table I). In this case, delivery of IdUrd to the left lobe required an initial passage of drug through the right lobe, followed by recirculation to the left lobe via systemic circulation. It is noteworthy that the tumor DNA level in the left lobe was lower than any values measured after intravenous drug delivery (Table I, patients A to E). This observation is consistent with presystemic elimination of IdUrd during its initial transit through the right lobe (first-pass effect). The overall selectivity of regional drug delivery in this case was $10.5 \%$ vs. $1.6 \%$, or about sevenfold greater. For two of three patients who received intraarterial IdUrd, DNA levels in normal liver were $\leqslant 1 \%$. For the third patient, a value of $2.4 \%$ was determined for substitution in DNA of normal liver (Table I).

In one case, the intravenous IdUrd infusion rate was 400 rather than $1000 \mathrm{mg} / \mathrm{m}^{2} /$ day for the 3-day infusion period (Table II, patient I). Incorporation of IdUrd into tumor DNA was proportionally reduced. For a similar dose of IdUrd $\left(450 \mathrm{mg} / \mathrm{m}^{2} /\right.$ day) a second drug (FdUrd at $2.4 \mathrm{mg} / \mathrm{m}^{2} /$ day) was simultaneously infused in five patients $(\mathrm{J}, \mathrm{K}, \mathrm{L}, \mathrm{N}$, and $\mathrm{P})$. Compared with patient $\mathrm{I}$, the incorporation of IdUrd into tumor DNA in patients $\mathbf{J}$ and $\mathrm{K}$ was three- to fourfold higher (Table II). Compared with the five patients who received single-agent IdUrd at an intravenous dosage of $1000 \mathrm{mg} / \mathrm{m}^{2} /$ day, patients $\mathrm{J}$ and $\mathrm{K}$ achieved about $50 \%$ higher incorporation rates. Thus the incorporation for the intravenous combination in these two patients was similar to that observed for intraarterial IdUrd as a single agent. The incorporation for patients $\mathrm{L}, \mathrm{N}$, and $\mathrm{P}$ was not greater than that for patient I, indicating no modulation. The average incorporation of IdUrd into tumor DNA for the five patients receiving the combination of FdUrd + IdUrd $(2.6 \%)$ was lower than for patients receiving IdUrd alone (3.1\%). The corresponding levels in DNA from normal liver were $<1 \%$ in four of five cases. Patient $\mathbf{J}$ had high levels of IdUrd in DNA from both tumor $(4.5 \%)$ and normal liver $(5.6 \%)$.

The HPLC results presented in Tables I and II represent average values for a tissue sample containing a mixture of cells that have no IdUrd incorporated into DNA and cells that have incorporated a variable amount of IdUrd. Flow cytometric analysis offers the opportunity to examine IdUrd incorporation in individual cells, based on the fluorescence associated with the antibody attached to DNA that contains IdUrd. For all patients studied by flow cytometric analysis, the tumor contained a substantially higher fraction of cells that had incorporated IdUrd as compared with normal liver (Table III).

For the 3-day intravenous infusion data, if one third of the tumor cells are labeled and the average dThd substitution is $3.1 \%$ (Tables I and II), then $10 \%$ is the average substitution for those tumor cells that contain IdUrd (Fig. 1). For the patient who received selective 
Table III. Flow cytometric analysis results:

Fraction of cells that contain IdUrd

\begin{tabular}{cccc}
\hline Patient & Normal liver & Right tumor & Left tumor \\
\hline F & $4 \%$ & $32 \%$ & $45 \%$ \\
G & $9 \%$ & $16 \%$ & \\
H & $4 \%$ & $38 \%$ & $48 \%$ \\
J & $14 \%$ & $25 \%$ & \\
K & $2 \%$ & $71 \%$ & \\
L & $5 \%$ & $*$ & \\
Median & $5 \%$ & $32 \%$ & \\
\hline
\end{tabular}

* No intact cells in specimen

arterial catheterization (Table I, patient $\mathrm{H}$ ), overall tumor substitution was $10.5 \%$, so the average substitution in those tumor cells that actually contain IdUrd would be $32 \%$.

Enzyme activities for TK and TS (Table IV) were measured on the same samples used for DNA analysis. TK activity in tumor samples tended to be higher than in normal liver samples, but the differences were not dramatic. TS activity in tumors was more impressively elevated, 10- to 35 -fold higher than in normal liver. The presurgical infusion of IdUrd could have inhibited both enzymes. The dose rate and period of infusion were all standardized for the four patients listed in Table IV. However, the length of time between the end of infusion and sample acquisition could not be carefully controlled and ranged from 2 to 6 hours.

Hepatic extraction of IdUrd can be calculated from the steady-state plasma levels for six patients who received separate intraarterial and intravenous infusions. The intravenous infusion rate was slightly lower than the intraarterial infusion rate (1000 vs. 1333 $\mathrm{mg} / \mathrm{m}^{2} /$ day), so a correction was made for this difference. As shown in Table V, the corrected extraction values ranged from $29 \%$ to $72 \%$ (median $70 \%$ ).

\section{DISCUSSION}

The results from this pharmacologic study indicate that IdUrd possesses several characteristics that would be expected to promote selective killing or radiosensitization of tumor cells. First, for intravenous delivery it was shown that tumor cells preferentially incorporate IdUrd compared with normal liver cells. Second, when the intraarterial route was used, there was additional selectivity for target cells. Tumor incorporation of IdUrd was higher, and first-pass hepatic extraction lowered systemic tissue exposure. Third, biochemical modulation with FdUrd or other drugs may provide some increased incorporation of IdUrd into tumor DNA.

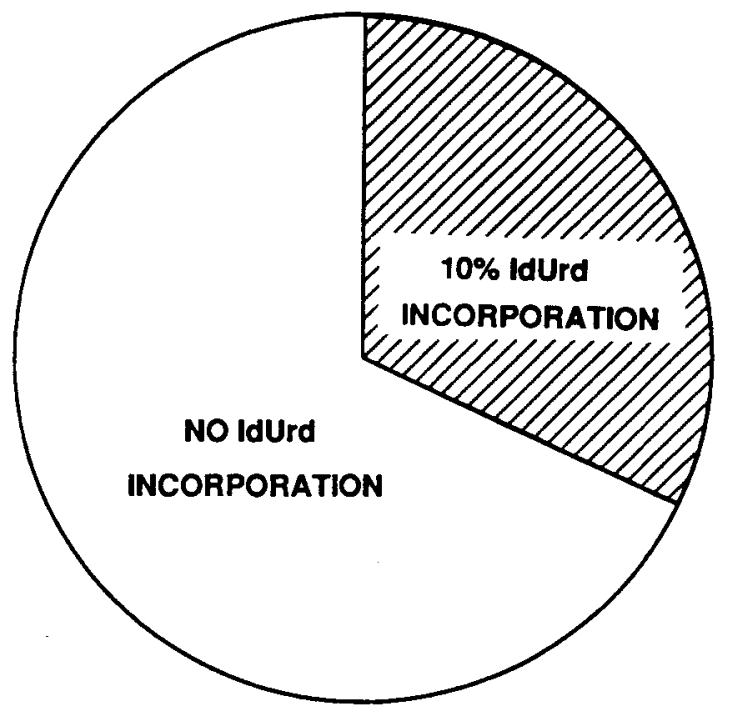

\section{HOMOGENATE $=3 \%$ IdURd INCORPORATION}

Fig. 1. Diagram of IdUrd distribution within hepatic tumor after 3 days of intravenous delivery at $1000 \mathrm{mg} / \mathrm{m}^{2} /$ day. Overall average of $3 \%$ substitution composed of two subpopulations: two thirds of cells have no IdUrd in DNA, and one third of cells have $10 \%$ of dThd in DNA replaced by IdUrd.

However, interpatient variability indicates that the particular combination used in this study was not practical. In fact, for some patients, the combination of FdUrd + IdUrd produced lower levels of IdUrd in tumor DNA than was achieved with single-agent IdUrd. Even a hint of tumor selectivity may be worth pursuing, because our previous study of DNA from normal granulocytes showed that FdUrd did not alter IdUrd levels. ${ }^{1}$

Flow cytometric analysis provided additional insight regarding both tumor cell kinetics and interpretation of HPLC results. Substantially more tumor cells than liver cells were labeled with IdUrd during the 3-day infusion period. In general, this result was expected, based on our rationale for selectively treating the cell population that was turning over more rapidly. However, the median value of $32 \%$ labeled tumor cells was perhaps higher than anticipated. This fraction corresponds to a potential tumor doubling time of 10 days. Because the net growth of these tumors is considerably slower, it would appear that substantial tumor cell death and subsequent necrosis is occurring. ${ }^{16}$

The optimal time for tumor exposure to drugs, es- 
Table IV. Comparison of enzyme activities in normal liver and tumors after 3-day continuous intravenous infusion of IdUrd at $1000 \mathrm{mg} / \mathrm{m}^{2} /$ day before biopsy

\begin{tabular}{cccccccc}
\hline & \multicolumn{3}{c}{$T K(p m o l / m i n / m g$ protein $)$} & & \multicolumn{3}{c}{$T S$ (pmol/min/mg protein) } \\
\cline { 2 - 3 } Patient & Normal & Right tumor & Left tumor & & Normal & Right tumor & Left tumor \\
\hline A & $*$ & 82 & 190 & & $*$ & 6.5 & 3.9 \\
B & 62 & 83 & 160 & & 0.20 & 7.0 & 6.6 \\
C & 15 & 190 & 92 & & 0.24 & 2.5 & 4.3 \\
D & 37 & 29 & 38 & & 0.12 & 1.2 & 1.1 \\
\hline
\end{tabular}

* No sample obtained.

Table V. Hepatic extraction* of IdUrd with intraarterial $\left(1333 \mathrm{mg} / \mathrm{m}^{2} /\right.$ day $)$ and intravenous (1000 $\mathrm{mg} / \mathrm{m}^{2} /$ day) infusions

\begin{tabular}{cccc}
\hline & \multicolumn{2}{c}{ Plasma IdUrd $(\mu \mathrm{mol})$} & \\
\cline { 2 - 3 } Patient & Intravenous & Intraarterial & Extraction \\
\hline A & 3.7 & 1.5 & $70 \%$ \\
C & 3.0 & 1.1 & $72 \%$ \\
D & 4.0 & 1.6 & $70 \%$ \\
E & 2.5 & 1.4 & $58 \%$ \\
I & 3.0 & 1.1 & $72 \%$ \\
M & 2.0 & 1.9 & $29 \%$ \\
\hline
\end{tabular}

*Extraction is calculated from the difference in steady-state plasma levels, corrected for the change in infusion rates.

pecially cell cycle-specific agents, is closely related to their potential doubling time. Based on this rapid turnover time for metastatic tumors in the liver, treatment protocols that provide 14-day drug exposure ${ }^{1,17,18}$ would be favored over 1- to 5-day infusion periods.

Due to the difficulties of using flow cytometric analysis to quantitate IdUrd incorporation into DNA ${ }^{19}$ (Speth et al., unpublished data), only qualitative data were obtained by these methods. However, based on both the flow cytometric and HPLC results, we have inferred that 3 days of intravenous drug delivery produced an average IdUrd substitution for dThd of $10 \%$ (in those tumor cells that contain IdUrd). Because the actual exposure durations during treatment are 10 to 14 days, additional tumor cells will incorporate IdUrd and there may also be some increased incorporation in cells already containing IdUrd. Based on a variety of studies in vitro and in vivo, ${ }^{20}$ at least a doubling of radiation effectiveness would be expected at this level of replacement. For selective arterial delivery, we inferred DNA substitution levels $>30 \%$ in tumor cells containing IdUrd, which would suggest radiation enhancement of at least fourfold.

It should be recognized that not all cells that contain
IdUrd have entered the S-phase or divided. Some cells may have incorporated IdUrd during conservative or repair DNA synthesis. If the mechanism of action of IdUrd is dependent only on incorporation into DNA, the details of the DNA synthetic process are not relevant. However, it is possible that some of the cytotoxic effects of IdUrd are caused by interruption with specific steps in DNA synthesis. These details are beyond the scope of the current studies.

Historically, colorectal cancer is considered to have de novo resistance to chemotherapy. A variety of mechanisms could be responsible for this pattern of resistance. For FdUrd and IdUrd, deletion of TK has been suggested as one resistance phenotype and is readily demonstrable in cell culture studies. ${ }^{21}$ The results of these studies (both direct TK assays and IdUrd in DNA) strongly reject TK deletion as a source of clinical resistance de novo. Acquired resistance via TK deletion is not addressed by the present work.

In addition to considerations regarding optimal exposure time, there is also a need to define the most appropriate infusion rate or exposure concentration. In general, the highest tolerable infusion rate is desirable, but a lower infusion rate for a longer period of time may have some advantages. The utility of increasing the infusion period may be limited by saturation of drug activation processes. The most direct approach would be to examine incorporation into DNA vs. the infusion rate. The present study did not have adequate numbers of patients to pursue this parameter, but does demonstrate the feasibility of such an approach.

Our prior attempts at pharmacologic studies with tumor biopsy specimens obtained through serendipitous events have never been satisfactory. The results of this study demonstrate that it is possible to organize the process of tissue acquisition to maximize pharmacologic knowledge. In addition to pharmacologic end points, it should be possible to determine some relationship for individual patients between studies of the biopsy results and treatment outcome when there is a 
close matching of infusion conditions before and after surgery.

The connection between presurgical and postsurgical treatments is not mandatory, and is not always desirable. It may be more logical to perform pilot studies of presurgical infusions before making a commitment to use any therapeutic approach for the treatment of specific tumor types. Several combinations of treatment parameters might be attempted before a suitable set of therapeutic conditions can be chosen. The results from this study have reaffirmed the selection of 14-day infusion periods for this tumor type and have also demonstrated that more work remains before it is reasonable to proceed with a therapeutic trial of FdUrd + IdUrd.

We acknowledge helpful discussions regarding this project with Dr. Paul H. Fischer at the University of Wisconsin and continuing encouragement from Drs. Eli Glatstein and Gisele Sarosy of the National Cancer Institute. Dr. James Cupp of the National Cancer Institute assisted with the flow cytometric analyses.

\section{References}

1. Chang AE, Collins JM, Smith R, et al. A phase I trial of iododeoxyuridine (IdUrd) administered regionally (IA) in patients with colorectal liver metastases. Proc Am Soc Clin Oncol 1988;7:96.

2. Benson AB, Trump DL, Cummings KB, Fischer PH. Modulation of 5-iodo-2'-deoxyuridine metabolism and cytotoxicity in human bladder cancer cells by fluoropyrimidines. Biochem Pharmacol 1985;34:3925-31.

3. Erikson RL, Szybalski W. Molecular radiobiology of human cell lines. III. Radiation-sensitizing properties of 5-iododeoxyuridine. Cancer Res 1963;23:122-30.

4. Jaffe JK, Prusoff WH. The effect of 5-iododeoxyuridine upon the growth of some transplantable rodent tumors. Cancer Res 1960;20:1383-8.

5. Berry RJ, Andrews JR. Modification of the radiation effect on the reproductive capacity of tumor cells in vivo with pharmacological agents. Radiat Res 1962;16:84-8.

6. Calabresi P, Creasey WA, Prusoff WH, Welch AD. Clinical and pharmacological studies with 5-iodo-2'deoxyuridine. Cancer Res 1963;23:583-92.

7. Klecker RW, Jenkins JF, Kinsella TJ, Fine RL, Strong JM, Collins JM. Clinical pharmacology of 5-iodo-2'deoxyuridine and 5-iodouracil and endogenous pyrimidine modulation. Clin Pharmacol Ther 1985;38:4551 .
8. Collins JM. Pharmacologic rationale for hepatic arterial therapy. Recent Results Cancer Res 1986;100:140-7.

9. Belanger K, Collins JM, Klecker RW. Technique for detection of DNA nucleobases by reversed phase highperformance liquid chromatography optimized for quantitative determination of thymidine substitution by iododeoxyuridine. J Chromatogr 1987;47:57-63.

10. Belanger K, Klecker RW, Rowland J, Kinsella TJ, Collins JM. Incorporation of iododeoxyuridine into DNA of granulocytes in patients. Cancer Res 1986;46:6509-12.

11. Speth PAJ, Kinsella TJ, Belanger K, et al. Phase I and clinical pharmacologic study of iododeoxyuridine incorporation into DNA of granulocytes modulated by fluorodeoxyuridine. Cancer Res 1988;48:2933-7.

12. Bradford MM. A rapid and sensitive method for the quantitation of microgram quantities of protein utilizing the principle of protein-dye binding. Anal Biochem 1976;72:248-54.

13. Armstrong RD, Diasio RB. Improved measurement of thymidylate synthetase activity by a modified tritiumrelease assay. J Biochem Biophys Methods 1982;6: 141-7.

14. Taylor AT, Stafford MA, Jones OW. Properties of thymidine kinase partially purified from human fetal and adult tissue. J Biol Chem 1972;247:1930-5.

15. Gronowitz JS, Kallander CFR. Optimized assay for thymidine kinase and its application to the detection of antibodies against herpes simplex virus type $1-$ and $2-$ induced thymidine kinase. Infect Immun 1980;29:42534.

16. Denekamp J. The cellular proliferation kinetics of animal tumors. Cancer Res 1970;30:393-400.

17. Chang AE, Schneider PD, Sugarbaker PH, Simpson C, Culnane M, Steinberg SM. A prospective randomized trial of regional versus systemic continuous FUDR chemotherapy in the treatment of colorectal liver metastases. Ann Surg 1987;206:685-93.

18. Kemeny N, Daly J. Preliminary results of a randomized study of intrahepatic infusion versus systemic infusion of 5-fluoro-2'-deoxyuridine for metastatic colorectal carcinoma. Recent Results Cancer Res 1986;100:171-8.

19. Dolbeare F, Beisker W, Pallvicini MG, Vanderlaan $M$, Gray JW. Cytochemistry for bromodeoxyuridine/DNA analysis: stoichiometry and sensitivity. Cytometry 1985; 6:521-30.

20. Szybalski W. X-ray sensitization by halopyrimidines. Cancer Chemother Rep 1974;58:539-57.

21. Keoffler HP, Yen J, Carlson J. The study of human myeloid differentiation using bromodeoxyuridine (BrdU). J Cell Physiol 1983;116:111-7. 